\title{
Hollow-Core Optical Fibers
}

\section{Matej KOMANEC, Daniel DOUSEK, Dmytro SUSLOV, Stanislav ZVANOVEC}

Dept. of Electromagnetic Field, Faculty of Electrical Engineering, Czech Technical University in Prague,

Technicka 2, 16627 Prague, Czech Republic

komanmat@fel.cvut.cz

Submitted July 14, 2020 / Accepted July 28, 2020

\begin{abstract}
Today hollow-core optical fibers (HCF) are on the verge of surpassing the attenuation benchmark of silica single-mode optical fibers used in optical communication. Compared to solid-core optical fibers, HCFs exhibit ultra-low nonlinearity, high damage threshold, low latency and temperature insensitivity, making them ideal candidates for high-speed data communication, high-resolution sensing, high-power delivery and precise interferometry. The main challenges of low insertion loss, suppressed back-reflections and fundamental mode coupling must be addressed to incorporate HCFs into existing fiber-optic systems to fully exploit their potential.
\end{abstract}

This paper provides an overview of the HCF history, from early papers in the 1980s, over the invention of photonicbandgap HCFs, to the recent achievements with antiresonant HCFs. Then light guiding mechanisms are presented and key HCF properties are discussed. Interconnection techniques to standard optical fibers are compared with respect to possible HCF applications. Fusion splicing results are presented with an alternative interconnection solution based on a modified fiber-array technique newly developed by our team. Finally, cutting-edge HCF applications that take advantage of our HCF interconnection, are discussed.

\section{Keywords}

Hollow-core fibers, photonic crystal fibers, antiresonant, photonic bandgap, interconnection, Fabry-Perot

\section{Introduction}

Silica single-mode optical fibers (SMFs) form the core of today's high-capacity telecommunication networks. However, network capacity is limited and a so-called "capacity crunch" is inevitable in the near future. Further improvement of the SMF performance will not be possible due to the physical limit of the Rayleigh scattering and the nonlinear Shannon limit [1]. Today's record-low attenuation for SMF of only $0.14 \mathrm{~dB} / \mathrm{km}$ at $1550 \mathrm{~nm}$ was achieved in 2018 [2].
Contrary to solid-core fibers, guiding light over long lengths in air (ideally in a vacuum) is extremely appealing. Hollow-core optical fibers (HCFs) have an air-filled core surrounded with microstructured glass cladding allowing high level of light confinement. Figure 1 gives an example of a 19-cell hollow-core photonic bandgap fiber (PBGF).

HCFs offer extremely low nonlinearity [3], low latency [4], high damage threshold [5] and temperature insensitivity [6-8]. HCFs can be advantageously used in many applications, e.g., long-length gas cells [9], high-power delivery [10], pulse compression [11], nonlinear phenomena [12], mid-infrared (MIR) propagation and sensing [13], MIR gasfilled lasers [14], ultra-precise fiber-optic gyroscopes [15] or Fabry-Perot resonators [16].

In telecommunications, $\mathrm{HCF}$ are now challenging the attenuation of standard SMFs [17]. An $11 \mathrm{~km}$-long HCF has already been drawn [18], while predictions of a more than $100 \mathrm{~km}$-long HCF drawing were presented in [19]. To effectively use HCFs in conventional fiber-optic systems, it is essential to connect HCFs to solid-core optical fibers, in most cases to SMFs. Three main challenges exist for such an HCFSMF interconnection: $i$ ) the air-silica boundary causing unwanted back-reflections; ii) state-of-the-art low-loss HCFs have a significantly larger mode-field diameter (MFD) compared to SMFs; and iii) HCFs with large MFD are inherently multi-modal, therefore higher-order mode (HOM) excitation must be suppressed to ensure only fundamental mode coupling.

Fusion splicing is a method that is typically used for permanent, low-loss interconnection of solid-core optical fibers. This method can be reasonably well applied [20] to the HCF-SMF interconnection, but does not address backreflections that occur on a glass-air interface. To suppress back-reflections, angled-splicing of HCFs was proposed, but proved to be quite lossy [21], [22].

We have developed an alternative approach for an HCFSMF interconnection based on a modified fiber-array technology [23], which solves the issue with back-reflections by applying optical coatings (optical coatings cannot be used in fusion splicing because of high temperatures). Furthermore, fundamental mode coupling is achieved by using mode-field adapters in the form of graded-index multimode fibers. 


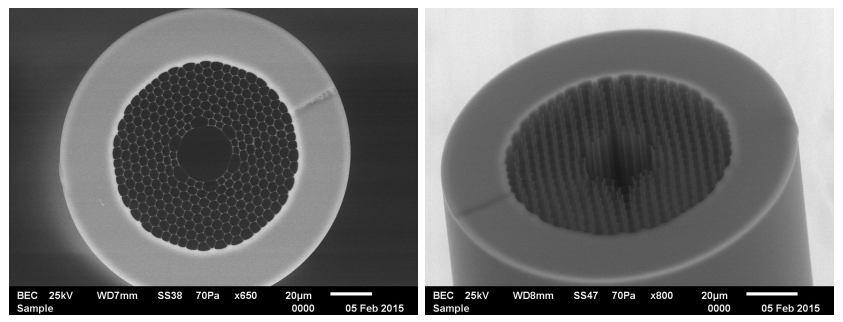

Fig. 1. Photographs of a 19-cell PBGF developed at the University of Southampton, acquired by a scanningelectron microscope.

This paper begins with a historical overview of the evolution of HCFs from the first real HCF samples to current state-of-the-art hollow-core nested antiresonant nodeless fibers (NANFs) with only $0.28 \mathrm{~dB} / \mathrm{km}$ attenuation at $1550 \mathrm{~nm}$ [17]. The section after the historical overview discusses the main HCF guidance mechanisms, from Bragg fibers, PBGFs to antiresonant fibers (ARFs), followed by a section summarizing HCF key properties, comparing PBGFs and ARFs, which are the main focus of this article. In the next section we show HCF interconnection techniques. Fusion splicing results are compared to our modified fiber-array technology. Advantages of our interconnection technique are discussed with regard to HCF applications in the last section.

\section{Historical Overview}

The idea of wave guidance in a hollow-core has existed since the end of the 19th century, when J. Thomson [24] and Lord Rayleigh [25] first discussed the possibility of metallic waveguides. Later in the 1960s, at the Bell labs, E. A. J. Marcatili and R. A. Schmeltzer [26] proposed a hollow-core metal-coated dielectric waveguide for short-range transmission of millimeter waves. The main length-limiting factor was attributed to waveguide bend-induced losses, e.g., a minimal attenuation of $1.85 \mathrm{~dB} / \mathrm{km}$ was predicted, whereas the attenuation doubled for a curvature radius of $R \sim 10 \mathrm{~km}$. With the advent of optical fibers later in the 1960s, the focus had shifted to solid-core fibers and the development of hollowcore waveguides for light delivery was significantly limited.

HCFs first appeared in the early 1980s in the form of hollow-core metal-coated fibers, which were designed for the $10.63 \mu \mathrm{m}\left(940 \mathrm{~cm}^{-1}\right)$ band to guide light from $\mathrm{CO}_{2}$ lasers [27]. These hollow-core fibers were made of $\mathrm{Pb}$-oxide glass and exhibited attenuation of $7.7 \mathrm{~dB} / \mathrm{m}$. Just ten years later, in 1991, silica-glass-based $\mathrm{HCF}$ was presented for $\mathrm{CO}_{2}$ laser delivery with attenuation below $1 \mathrm{~dB} / \mathrm{m}$ [28]. It is important to mention that these HCFs typically had core diameters larger than $1 \mathrm{~mm}$.

In 1993 two interesting studies on HCFs appeared that were based on the silica-air design. First, HCFs in the vicinity of $10 \mu \mathrm{m}$ were used to measure gas concentration where $\mathrm{HCF}$, with a $1.5 \mathrm{~mm}$ inner core diameter and of $1 \mathrm{~m}$ length, acted as a gas cell to analyze $\mathrm{NH}_{3}$ content [29]. Second, an interferometric HCF-based fiber sensor was published in [30], where the HCF was formed by a glass capillary with a $70 \mu \mathrm{m}$ inner diameter and length of $137 \mu \mathrm{m}$. Later, in 1995, a simple-glass capillary HCF was used to transport atoms by optical forces [31]. In this work the main limitation originated from glass capillary attenuation, proving the need for better light guidance. Annular core fibers were mentioned as a possible substitute for glass capillaries.

Bragg HCFs have subsequently superseded the older HCF-type metal-coated capillary fibers [28] thanks to their lower attenuation at identical wavelengths. To give an example, the first Bragg HCF, denoted as an Omniguide fiber, was presented in 2002 [32] with high-refractive-index glass and a low-refractive-index polymer microstructure. Omniguide fibers exhibited less than $1 \mathrm{~dB} / \mathrm{m}$ attenuation at $10.6 \mu \mathrm{m}$ while it was possible to get tens of meters of Omniguide fiber in a single draw. Later the focus was primarily placed on Bragg fibers from pure silica where the rings were held together by glass struts [33].

Parallel to this, in 1996, a fundamental breakthrough was made in the field of optical fibers when J. C. Knight published experimental results of the very first photonic crystal fiber (PCF) and thus revolutionized the fiber-optic world [34]. The idea of PCF came from P. St. J. Russell and was based on the paper by Y. Jablonovitch [35] and S. John [36], who first showed the possibilities of 2D and 3D photonic crystals and derived the photonic bandgap conditions. The invention of PCFs allowed unprecedented freedom in PCF parameter tailoring (such as the chromatic dispersion curve, zero-dispersion wavelength, single-mode cut-off wavelength, mode-field diameter) which can be easily modified by changing the design of the PCF microstructure. Endlessly-single mode PCFs appeared a year after [37], group-velocity dispersion management became possible [38] and soon supercontinuum generation was first demonstrated using PCFs with zero-dispersion wavelength at $800 \mathrm{~nm}$ producing broadband radiation from visible to near-infrared [39].

The first photonic crystal HCF was presented in 1999 by Cregan et al. [40], members of the P. St. J. Russel team at the University of Bath, where most of the pioneering research in HCFs was carried out in the following years. In [40], a silicabased HCF with honeycomb microstructure and a core diameter of $14.8 \mu \mathrm{m}$ was fabricated. The guidance mechanism was attributed to the $2 \mathrm{D}$ photonic bandgap (PBG) effect. This first hollow-core photonic bandgap fiber (HC-PBGF, or more simply PBGF) led to numerous application areas where HCF were afterwards advantageously used such as gas sensing [41], gas-filled lasers [42], fiber-optic gyroscopes [15], high-speed data transmission [17], and many more [5, 16,43].

Considering telecommunication, i.e. optical networks, the most important parameters are fiber attenuation in the $1550 \mathrm{~nm}$ band (denoted as C-band) and fiber transmission bandwidth. In 2002, a 7-cell PBGF with attenuation of $13 \mathrm{~dB} / \mathrm{km}$ was reported [44], while, in 2004, attenuation was improved to $1.7 \mathrm{~dB} / \mathrm{km}$ [45] and to $1.2 \mathrm{~dB} / \mathrm{km}$ [46] in 2005 


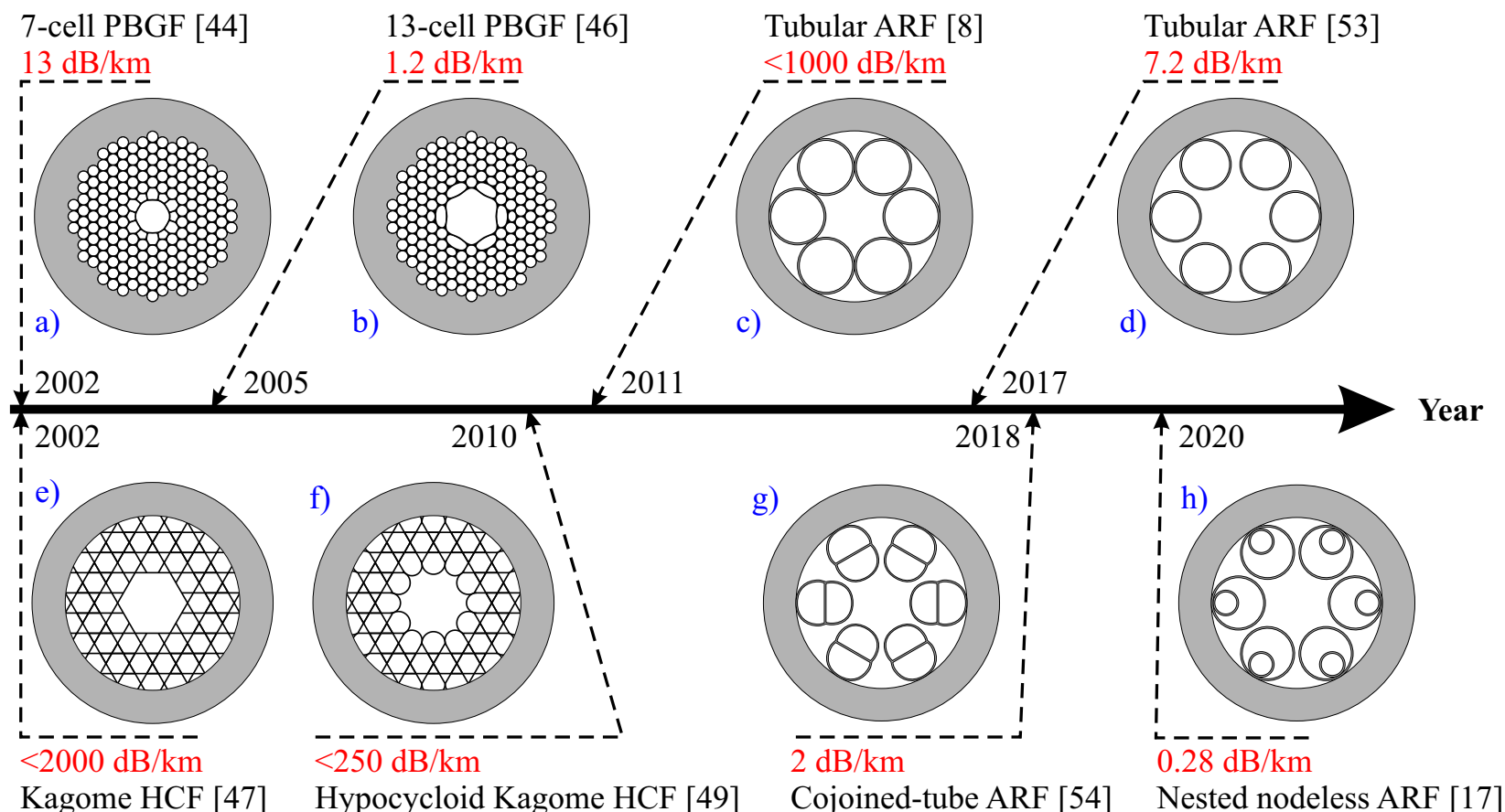

Fig. 2. Timeline of the hollow-core optical fiber evolution including both fiber design and attenuation milestones, values are given for the wavelength of $1550 \mathrm{~nm}$

which is, until today, still the record-low attenuation for PBGFs (see Fig. 2b). The design of the PBGF eventually limited the progress in achieving low-attenuation and broadband performance (e.g., in [46] the achieved bandwidth was only $70 \mathrm{THz}$ ) and an alternative HCF design was pursued.

The first alternative appeared in 2002 when a new type of HCF, denoted as Kagome HCF, was invented [47]. Kagome HCFs provide an extremely delicate structure of thin triangular-lattice struts with no cladding nodes (see Fig. 2e), which leads to multi-band transmission and much lower mode-field overlap with the glass cladding thanks to inhibited coupling. Even then was the attenuation of Kagome HCF higher than that of PBGFs by more than two orders of magnitude due to the high confinement loss [48].

The next milestone in HCF development occurred in 2010 with the development of negative curvature Kagome HCFs, denoted as hypocycloid fibers [49]. These Kagome HCFs worked on the principle of antiresonance and are thus a representative of an ARFs. The negative curvature represents the shape of the first ring around the ARF core (see Fig. 2f) which led to a decrease of fiber attenuation down to hundreds of $\mathrm{dB} / \mathrm{km}$ with a bandwidth of $1000 \mathrm{~nm}$. Although the attenuation of this negative curvature Kagome HCF was significantly higher than that of PBGF, the bandwidth was superior to that of the PBGF. Later, in 2016 a Kagome HCF with attenuation of $12.3 \mathrm{~dB} / \mathrm{km}$ at $1 \mu \mathrm{m}$ was presented [50].

Parallel efforts focused on exploiting the negative curvature while simultaneously reducing the microstructure complexity. In 2010 and 2011, the first ARFs with a simplified design appeared, showing a simplified PBGF lattice [51], a simplified hypocycloid Kagome lattice [52] and, finally, a tubular lattice [8]. These ARFs did not require a periodic lattice and worked just on the principle of antiresonance. Among the lattice variants, the tubular ARF provided the simplest design and best performance and has been further developed (see Fig. 2c, d). The lowest current attenuation of a single-ring tubular ARF is $7.7 \mathrm{~dB} / \mathrm{km}$ at $750 \mathrm{~nm}$ [53].

The results presented in [53] were impressive, though still far from conventional SMFs. Three years earlier, in 2014, a fundamental study was published [6] showing the potential of ARFs when including an additional (nested) resonator inside of each existing tubes, forming the so-called nested antiresonant nodeless fibers (NANFs). It was envisioned that NANFs could eventually surpass the attenuation of other HCF types and eventually that of SMFs. This is due to the negligible optical field overlap with the glass leading to low surface scattering losses. Generally, ARFs suffered from significantly higher confinement losses, however those were addressed by the proposed NANF design by including more antiresonant elements.

By 2018 a cojoined-tube fiber (CTF) with a minimal loss of $2 \mathrm{~dB} / \mathrm{km}$ at $1512 \mathrm{~nm}$ was demonstrated [54] (see Fig. 2g). In parallel, NANFs have undergone rapid development (see Fig. 2h). NANF with only $1.3 \mathrm{~dB} / \mathrm{km}$ was presented the same year [55] and this attenuation value was significantly decreased just a year later by NANF with attenuation of $0.65 \mathrm{~dB} / \mathrm{km}$ [56]. Recently, in 2020, a NANF with a recordlow attenuation of only $0.28 \mathrm{~dB} / \mathrm{km}$ has been presented [17], challenging the long-held record of SMFs. 


\section{HCF Fabrication and Waveguiding}

The most common fabrication method of HCFs is the stack-and-draw principle [34] where multiple glass capillaries are stacked in a large capillary, then drawn to a preform, and, finally, drawn to the final HCF structure [40]. Extreme care needs to be taken especially when applying specific pressures or a vacuum to the capillaries to achieve the desired HCF design. Less common methods to obtain a preform are extrusion, drilling or sol-gel casting, techniques often used for short fiber samples and glass materials other than silica (e.g., chalcogenide glass). As HCF drawing is a time-consuming and extremely costly process, virtual HCF drawing was presented in 2014 by G. Jasion in [57].

$\mathrm{HCF}$ waveguiding principles can be divided into three categories according to HCF design:

- Bragg hollow-core fibers with a layered structure of cladding (1D photonic crystal) - find example in Fig. 3.

- Hollow-core photonic bandgap fiber (PBGF) with a large number or periodic air-holes arranged in rings surrounding the central air-core - see example in Fig. 1, 2a and 2b.

- Antiresonant hollow-core fiber (ARF) with a Kagome or a simple cladding structure - examples given in Fig. 2c-h.

This section overviews the basic principles for each $\mathrm{HCF}$ type mentioned-above with focus on ARFs which are the state-of-the-art HCFs.

\subsection{Bragg HCF Guidance}

Bragg HCFs have a simple inner structure that can be described as a 1D photonic crystal formed by a series of layers with periodically changing refractive indices $n_{1}$ and $n_{2}$. Bragg's law is given as:

$$
N \lambda=2 \Lambda \sin \phi
$$

where $N$ is a positive integer, $\lambda$ is the wavelength, $\Lambda$ is the period of the cladding and $\phi$ is the angle of the incident wave. Total reflection then occurs for a range of wavelengths around $\lambda$ and a range of angles around $\phi$. To acquire high reflectance, i.e. low guiding losses, a significant difference in refractive indices $\Delta n$ (high $n_{1} / n_{2}$ ratio) is needed. This condition applies to glass materials having high-refractive indices, thereby exhibiting higher material losses limiting possibly low Bragg HCF attenuation. However, for short ranges in order of meters attenuation is not critical and Bragg fibers are, therefore, an excellent candidate for $\mathrm{CO}_{2}$ laser delivery.
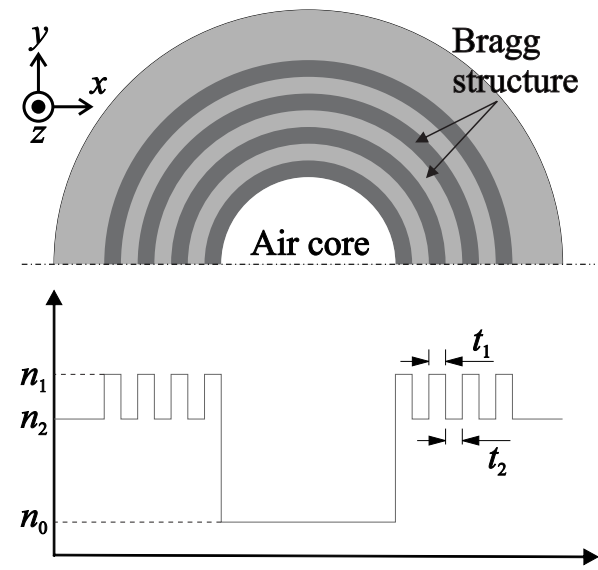

Fig. 3. Example of a Bragg fiber structure with its refractive index profile, $n_{1}$ and $n_{2}$ are refractive indices of the Bragg layers, $n_{0}$ is refractive index of air, $t_{1}$ and $t_{2}$ are layer thicknesses.

\subsection{Photonic Bandgap Guidance}

Hollow-core PBGF is formed by introducing a defect in the periodic photonic crystal structure. Light is then trapped in the defect as it cannot escape through the cladding due to the photonic bandgap (PBG) effect, and is guided along the fiber. The defect can be created by removing a capillary from the center of the preform (e.g., to form a symmetric low-index core we can remove 7, 19 or 37 capillaries, thus so-called 7-,19- and 37-cell PBGFs are drawn).

The analogy between electronic bandgaps and photonic bandgaps originates from the periodic arrangement of atomic potentials and two different dielectrics, respectively. The periodicity of the two dielectrics (representing the cladding) gives rise to a frequency band where propagation of photons is forbidden.

The PBG effect is described in great detail in [40,58,59]. Here we briefly overview three approaches, from the oldest to the current one:

1. Using numerical approaches from solid-state physics.

2. Brute-force techniques, such as a finite difference methods, finite element method (FEM) or plane-wave expansion.

3. An antiresonance description of a number of resonators in the cladding.

The first description of the guidance mechanism, based on the analogy with solid-state physics, appeared in 1999 [40] and presented the 2D PBG effect principle, which was denoted as "frustrated tunneling PBG guidance". The cladding structure was considered as a double layer dielectric stack with an air-core in between. Light was confined once the stacks provided PBG for a range of propagation constants $(\beta=k n \cos \phi)$ at fixed optical frequencies. 
In the following effort to find the best lattice configuration, numerical approaches from solid-state physics were applied to calculate the PBGs supporting the air-guided mode of a unit cell with periodic boundary conditions as a function of the wavevector direction [60], [61]. These first papers brought noteworthy PBGF design optimizations, such as a triangular lattice outperforming a honeycomb lattice [62] and the introduction of bandwidth scaling based on the air-filling fraction (percentage of air content to glass material) [63]. However, these approaches considered only a perfectly symmetric PBGF microstructure.

With rapid increase in computational power, methods such finite difference method [64] became more common. These methods allowed for a far more accurate description of mode distribution in $\mathrm{HCF}$ as they consider the real $\mathrm{HCF}$ microstructure instead of the idealized one, which was the case of previously used analytical models. However, these methods did not explain the physical mechanisms, nor did they provide any more-in-depth understanding. Nevertheless, they have since often been applied due to improved computational capacities and satisfactory approximate results.

In the last decade, researchers have moved towards describing PBGFs by antiresonance, which we will discuss in greater detail after introducing the basic antiresonance waveguiding principles.

\subsection{Antiresonant Guidance Mechanism}

For some HCFs the light guidance cannot be explained by the formation of PBGs as the glass membrane (strut) thickness $t$ is typically hundreds of nm, which is one or two orders of magnitude thicker than the boundary condition for PBG. Here, antiresonant reflection confines light in the air-core (or generally lower refractive index region) without the need for periodic cladding and the PBG effect. The antiresonant reflecting optical waveguide (ARROW) model has been often used to describe ARFs, where the first idea appeared in 2002 [65] and has been further evolved [66]. The principle of ARROW assumed high-index circular layers around the low-index (air) core, where each layer acts as a Fabry-Perot resonator.

We will describe the antiresonant guidance with simplified examples of a 1D slab waveguide, an annular core fiber and a negative curvature fiber. Then we will return to the PBG effect and describe its interpretation via antiresonance reflection.

\section{D Slab Waveguide Approach}

To understand the antiresonance principle, the example of a 1D slab waveguide is often given. The situation is depicted in Fig. 4 with $D_{\text {core }}>>\lambda$. The resonance condition (phase difference is $2 m \pi$ ) for the transversal wave vector $k_{\mathrm{T}}$ is described as [67]:

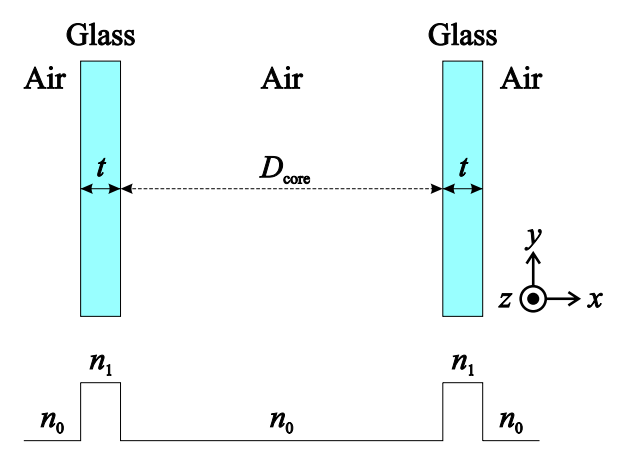

Fig. 4. 1D slab waveguide structure, glass with refractive index $n_{1}$, air with refractive index $n_{0}, t$ is the glass thickness and $D_{\text {core }}$ is the slab width corresponding the the fiber core diameter.

$$
k_{T}=\sqrt{k^{2} n_{1}^{2}-\beta^{2}}=k \sqrt{n_{1}^{2}-1}
$$

where we consider $n_{1}$ as the refractive index of the glass material and the refractive index of air is $n_{0}=1$. The parameter $m$ is a real positive integer and $t$ is the glass thickness. We can then find a resonance wavelength $\lambda_{\text {res }}$, where all the light is transmitted in the transversal direction given as [67]:

$$
\lambda_{\mathrm{res}}=\frac{2 t \sqrt{n_{1}^{2}-1}}{m}, \quad m=0,1,2, \ldots
$$

For wavelengths other than $\lambda_{\text {res }}$, light is confined inside the air-core with low leakage loss. The solution of the 1D slab waveguide based on anti-resonance leads to a number of resulting glass thicknesses based on $m$. These solutions provide high leakage loss for given wavelengths. Fiber transmission bands are present between them (see example cases given in [67]).

For the fundamental mode, not only does $t$ play a critical role, but also air-core diameter $D_{\text {core }}$. The transmission bands do not change with $D_{\text {core }}$, but leakage loss increases as $D_{\text {core }}$ gets larger [67].

\section{Annular Core Fiber}

Moving from the 1D slab waveguide to the simplest case of a fiber structure, we can assume a high-index glass ring around the air-core, which forms two reflective surfaces. This configuration is denoted as an annular core fiber and is depicted in Fig. 5. For a mode existing in the glass ring, the effective index is between that of glass and air. For a mode propagating in the air-core, the effective refractive index is lower than that of air. Depending on glass thickness $t$, multiple transmission bands will be present, with losses dependant on $t$ and $D_{\text {core }}$. The modes of the annular core fiber can be easily calculated using FEM [67] or mode-matching methods [68]

$$
k_{\mathrm{T}} t=\pi m,
$$




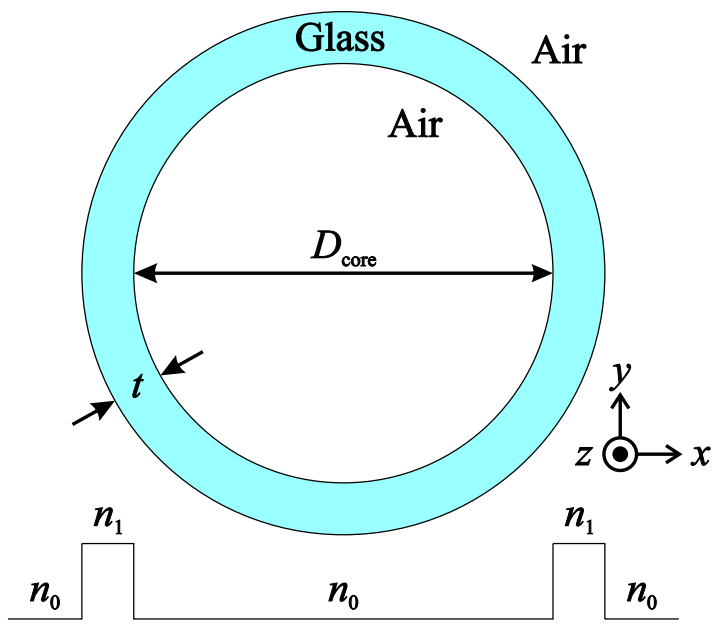

Fig. 5. Annular core fiber structure, glass with refractive index $n_{1}$, air with refractive index $n_{0}, t$ is the glass thickness, $D_{\text {core }}$ is the annular fiber core diameter and $z$ is the direction of light propagation.

\section{Negative Curvature Fiber}

Let us consider a simple tubular ARF, as shown in Fig. 6 with a set of capillaries around the central air-core, which are in touch with each other. The core boundary is now formed by glass membranes (capillary walls) having a negative curvature with respect to the radial direction. The overall geometry of such negative curvature fiber is described by $D_{\text {core }}$, capillary thickness $t$, capillary diameter $D_{\text {cap }}$ and the number of capillaries $p$ as [67]:

$$
D_{\text {core }}=\frac{D_{\text {cap }}+2 t}{\sin (\pi / p)}-\left(D_{\text {cap }}+2 t\right) \text {. }
$$

For negative curvature fibers, the effective refractive index of the fundamental mode is larger than that for the same $D_{\text {core }}$ of annular fibers due to the negative curvature, given an empirical 5\% increase [67]. This fact is interconnected with the required glass membrane thickness $t$, which is smaller for negative curvature fibers than for annular core fibers thanks again to the negative curvature effect [69].

Figure 7 shows an example of an advanced type of the negative curvature fiber with non-touching capillaries, parameter $g$ then defines the gap. These fibers eliminate the remaining glass nodes which are not in anti-resonance. The nodes can be seen e.g., in Fig. 6 at the point where the capillaries touch each other. The addition of the gap leads to better confinement of the core mode and therefore lower attenuation of the tubular ARF. Furthermore, HOMs are significantly attenuated due to the added gaps.

The effect of $D_{\text {core }}$ on transmission bands and leakage loss is identical to annular core fibers.

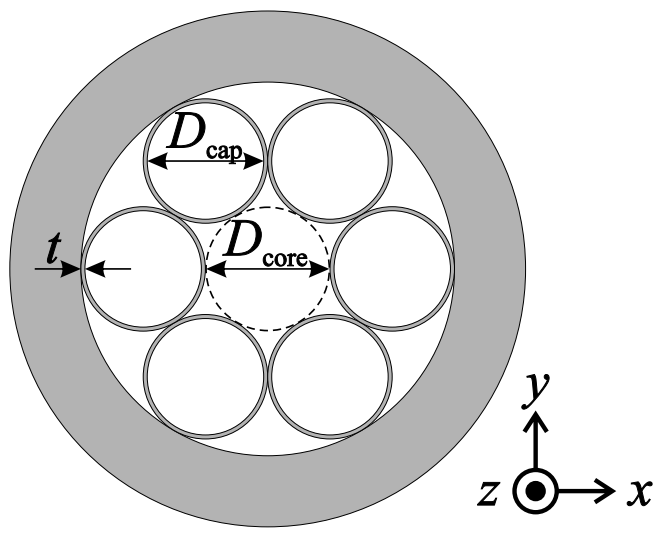

Fig. 6. Tubular fiber structure.

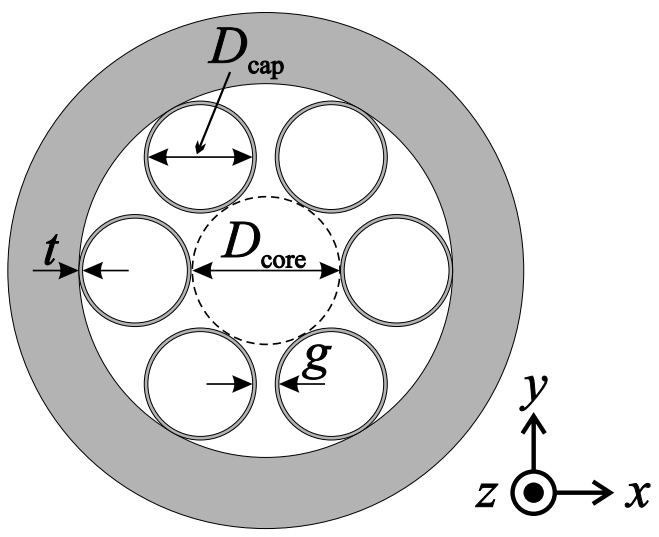

Fig. 7. Tubular fiber structure with non-touching glass capillaries.

\section{Inhibited Coupling}

Antiresonance prohibits the air-core mode from overlapping with the glass material (glass capillaries). This leads to low surface scattering and low material-induced attenuation which is required for low loss propagation. Nevertheless, to achieve competitive losses to standard SMFs greater coupling suppression between the air-core mode and the cladding modes is required. This coupling suppression is denoted as inhibited coupling [53]. Inhibited coupling is achieved by the already mentioned low overlap between the core and cladding modes and furthermore by a mismatch of core and cladding modes effective refractive indices.

For a more detailed description and illustrative calculated examples of the 1D slab waveguide, annular core and negative curvature fibers and inhibited coupling see [67].

\section{PBGF Described by Antiresonance}

In the last decade research has turned to antiresonance principles in order to describe light guiding mechanism of the PBGF [59]. The idea is illustrated in Fig. 8 showing a simplified formation of the photonic bandgap as the PBGF is being assembled. 


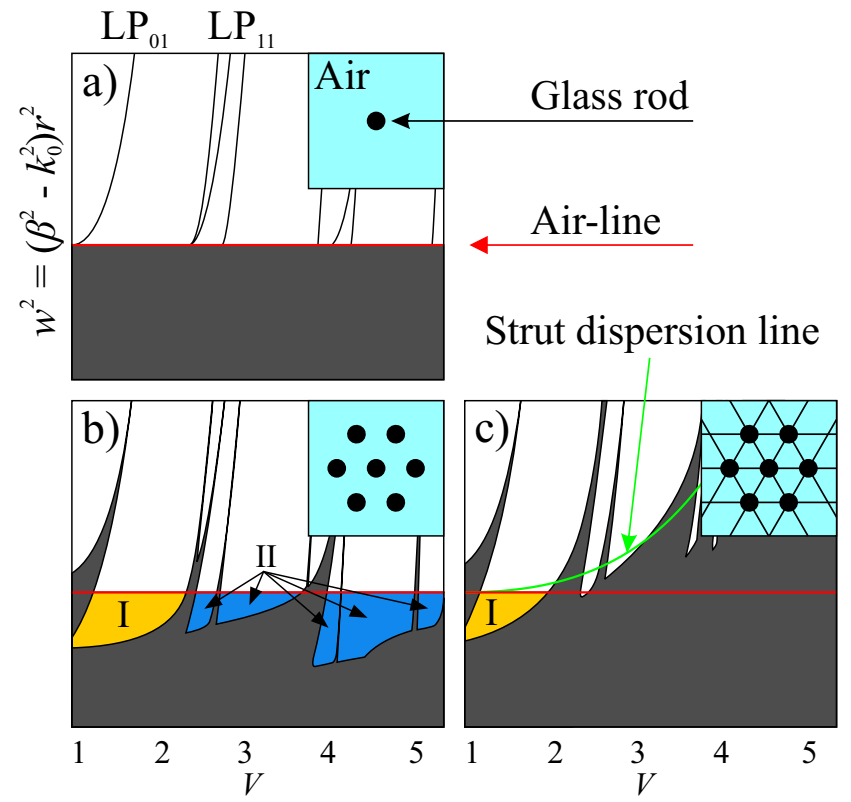

Fig. 8. Formation of an air-guiding PBG, simplified from [59].

At first, we assume just a single silica rod in an infinite air-cladding (see inset of Fig. 8a), the guided modes are described by the well-known dispersion equation, using the normalized frequency $V$ and rod radius $r$ as:

$$
V=\frac{2 \pi r}{\lambda}\left(n_{1}^{2}-n_{0}^{2}\right)
$$

Then we can set the air-line as given e.g., in [59] as:

$$
w^{2}=\left(\beta^{2}-k_{0}^{2}\right) r^{2}=0
$$

where $\beta$ is the propagation constant (in the direction of propagation) and $k_{0}$ is the wavenumber in air. No modes can propagate above air-line (in the white regions) as they are in antiresonance with the rod modes and also they cannot propagate in the cladding. Below the air-line is a continuum of plane-wave-like air modes [59], see Fig. 8a.

When more rods are arranged in a symmetric/periodic fashion to form a single ring around the central rod (see inset of Fig. 8b), the dispersion equation changes and conditions broaden around the particular mode cut-offs (intersection of the mode curves with the air-line). In fact, the rod modes become so expanded that they overlap with the other rod modes and a spatial superposition occurs. Meanwhile, periodic forbidden bands appear below the air-line (coloured regions in Fig. 8b, marked as I and II).

If we create a defect, i.e., remove one of the rods, light can be coupled into the defect region and propagate in the PBG regions. Further addition of more rods in the 2nd, 3rd, etc. rings increases the confinement (considering we create the defect in the fiber center). By placing the rods closer to each other (decreasing the so-called pitch) we decrease the bandwidth of the PBG while allowing more modes to propagate in the PBG, which is often unwanted as HOMs are detrimental to various applications.
To create a real PBGF, we need to interconnect the rods so that the fiber holds together. We achieve this by introducing struts (see Fig. 8c). The struts are not in antiresonance to the air-core mode (confined in the defect). We can see in Fig. 8c that high frequency PBGs disappeared (blue regions marked as II) due to the effective refractive index being raised by the glass struts above the air-line. This is the reason behind PBGF having only one transmission band in contrary to ARFs where multiple transmission bands are present.

\section{HCF Losses and Modes}

This section will briefly explain the main HCF parameters and state-of-the-art results.

\subsection{HCF Attenuation}

Hollow-core fibers are envisioned to surpass the minimal intrinsic attenuation of silica SMFs [2] in the near future. Currently, the lowest $\mathrm{HCF}$ attenuation at $1550 \mathrm{~nm}$ for PBGF is $1.2 \mathrm{~dB} / \mathrm{km}$, achieved in 2005 [46], and $0.28 \mathrm{~dB} / \mathrm{km}$ for NANF as presented in 2020 [17]. There is negligible Rayleigh scattering loss in HCFs compared to silica fibers, on the other hand, surface-scattering loss (SSL) and confinement loss (CL), i.e., leakage loss can be detrimental.

SSL is dominant for PBGFs. The struts supporting the rods in the PBGF microstructure are made as thin as possible to widen the transmission bandwidth and, thus, are not in anti-resonance. Therefore, a mode-field overlap with the struts occurs. This overlap results in scattering at the air-glass interface, which is dependent on the inner surface roughness and HCF non-uniformity. This roughness is caused by the surface capillary waves that are thermodynamically lockedin when the HCF cools during HCF drawing. Compared to the SSL effect, CL is negligible in PBGF thanks to the possibility of increasing the number of rings (resonators). Considering bending losses, PBGFs are the most resistant of all above-mentioned HCFs [70].

ARFs (excluding Kagome fibers) perform oppositely to PBGFs, regarding sources of fiber losses. Thanks to their negative curvature, inhibited coupling and antiresonance, SSL is negligible (there is minimal mode-field overlap with the glass material). For state-of-the-art NANFs, SSL is lower than $10^{-1} \mathrm{~dB} / \mathrm{km}$. Contrary to SSL, confinement loss is detrimental to many ARFs due to the gaps between tubes and since only one ring of the antiresonant structure is included. For ARFs, CL is typically around $10^{-6}$. NANFs have introduced a solution to increase the mode-field confinement by adding nested tubes and have thus achieved lower CL of only $10^{-8}$ [6]. In [6] it was also shown that for $D_{\text {core }}=50 \mu \mathrm{m}$, SSL and CL are equal, with CL scaling with the core radius $R_{\text {core }}$ as $R_{\text {core }}^{-8}$ and SSL with $R_{\text {core }}^{-3}$. Furthermore, F. Poletti predicted in [6] that for $D_{\text {core }}=40 \mu \mathrm{m}$ it would bring fiber attenuation to the $0.1 \mathrm{~dB} / \mathrm{km}$ level, which would surpass SMFs in the wavelength region of 1.5 to $2.3 \mu \mathrm{m}$. Increasing the size of $D_{\text {core }}$ promises to reach even lower fiber attenuation. 
The combination of negligible SSL and lowered CL led to NANFs with sub- $1 \mathrm{~dB} / \mathrm{km}$ attenuation achieved in 2019 [56] and 2020 [17].

\subsection{Higher-Order Modes}

To minimize SSL and reduce the mode-field overlap with glass material, PBGFs and ARFs are designed with a large $D_{\text {core }} / \lambda$ ratio (typically above 10 ). This leads to an increased number of guided modes and lower HOM attenuation. For PBGFs, the number of modes is given by the PBG - approximately 12 modes are present in case of a 7-cell PBGF, around 40 modes for 19-cell PBGF and approximately 80 modes in case of 37-cell PBGF [71]. In PBGF, the lowest-order HOM ( $\left.\mathrm{LP}_{11}\right)$ propagates with attenuation of only about 2.5 times larger than the fundamental mode $\left(\mathrm{LP}_{01}\right)$ and, therefore, HOMs can propagate even over longer PBGF lengths [70]. In NANFs HOMs propagate with attenuation in orders of hundreds or even thousands of $\mathrm{dB} / \mathrm{km}$, which allows effective single-mode guidance to be obtained even at short fiber lengths.

It is possible to suppress HOMs significantly by precise alignment of input light source (either free-space optics or fiber) while exciting only the fundamental mode. We show a measured interference pattern of the fundamental mode $\left(\mathrm{LP}_{01}\right)$ with HOMs for a 10-m-long PBGF in Fig. 9a). From this interference pattern and by using a Fourier transform, it is possible to calculate the relative amplitude of the propagating modes and know which HOMs propagate in the particular HCF [72]. This is depicted in Fig. 9b), where we can also see greater than $30 \mathrm{~dB}$ suppression of HOMs. In this case, mode-field adapters based on a graded-index multimode fibers were used to match the mode-field of an SMF to a PBGF [23] and, according to the match quality, we observed interference (HOM amplitude) of various levels.
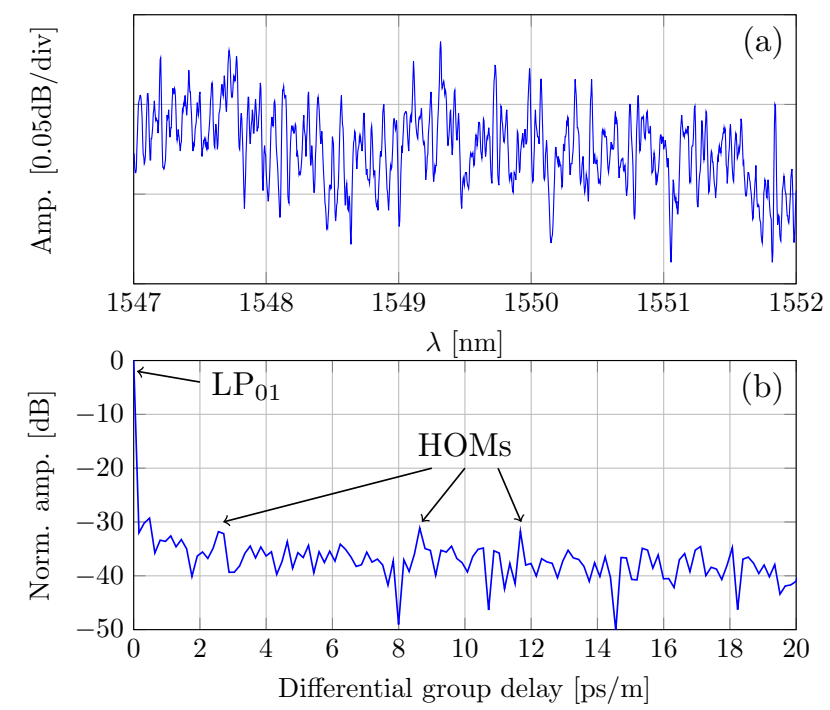

Fig. 9. Higher-order mode interference pattern in a $10-\mathrm{m}$-long PBGF. (a) Measured using optical spectrum analyzer and (b) it's Fourier transform.

\section{HCF to SMF Interconnection}

The practical implementation of HCFs is generally limited to laboratory applications. This is due to the difficulty in connecting HCFs with existing optical systems that are mostly based on standard SMFs. This is especially true for 19- and 37-cell PBGFs and the state-of-the-art NANFs having $D_{\text {core }}$ over $30 \mu \mathrm{m}$. Additionally, precise MFD matching must be carried out so that HOMs are not excited. Using lenses with precise alignment is not a viable long-term solution due to limited time stability. Connectors are challenging as well, as the exposed HCF is susceptible to mechanical damage or a humid environment [73]. Therefore permanent and hermetic interconnection is required, as with conventional fiber-optic components.

Key requirements on the interconnection, apart from being permanent and hermetic, are:

- Low insertion loss (IL)

- Suppressed back-reflections on the silica-air interface, i.e., low return loss, RL

- Strict fundamental mode excitation (suppression of HOMs)

\subsection{Fusion Splicing}

A common practice of creating a permanent interconnection of two optical fibers is fusion splicing. This is typically done using an arc-discharge that heats the two fiber ends, which are then pressed together to form a permanent, robust, repeatable and low-loss splice. When splicing two SMFs we can obtain virtually loss-less interconnection with no unwanted back-reflections. After the appearance of HCFs, modified splicing techniques have emerged with focus on maintaining the delicate microstructure, which easily collapses if overheated [9], [74]. The main modification is typically done by using a heating offset (by arc, filament or $\mathrm{CO}_{2}$ laser) so that the SMF is heated more than the PCF and the HCF is then softly pushed onto the HCF. Unfortunately, this generally leads to low strength splices.

The first efforts in HCF splicing occurred in 2005, where the effect of an HCF microstructure collapse via an arcdischarge was studied [74], and in the same year, HCFs were spliced for use in gas-cells [9] with IL of $1.7 \mathrm{~dB}$. In 2006 a deeper HCF splicing analysis was published [75], focusing on 7-cell (MFD 7.5 $\mu \mathrm{m})$ and a 19-cell (MFD $~ 13 \mu \mathrm{m})$ PBGFs. For an SMF to 7-cell PBGF splice, IL of 1.5-2.0 dB was observed for SMF-PBGF transition and 2.6-3.0 dB for the HCF-SMF transition. In the case of the 19-cell PBGF, IL was $0.3-0.5 \mathrm{~dB}$ and over $2.0 \mathrm{~dB}$ for SMF-HCF and HCF-SMF transitions, respectively. This unbalanced result of SMFHCF and HCF-SMF insertion loss is extremely important, as it shows a huge effect of HOM excitation on measured IL once the MFD and numerical aperture of the SMF and $\mathrm{HCF}$ are not well matched. It is necessary to always measure two splices (generally interconnections), the input and output 
together so that the effect of the HOM is neglected. Or if just one splice is evaluated, fundamental mode coupling must be ensured or the effect of the HOM corrected (using a long enough HCF so that all HOMs would be attenuated).

Further attempts at HCF-SMF splicing brought improved IL and were focused on suppressing unwanted backreflections that occur at the glass-air interface. In 2007, splicing of flat and angled-cleaved 7-cell PBGFs was presented [21], with IL of $0.9 \mathrm{~dB}$ and $3.0 \mathrm{~dB}$ for flat and angled-cleaved HCFs, respectively, with RL of $-16 \mathrm{~dB}$ and $-60 \mathrm{~dB}$. In 2016, splicing of 7-cell and 19-cell angled-cleaved PBGFs [22] brought improved IL of 1-2 dB with slightly lower RL of $-50 \mathrm{~dB}$. IL in this work was measured including HOMs which explains the great range of obtained IL values, furthermore, the obtained cleave angle variation was significant, from 7 to 12 degrees. In the same year, high-strength fusion splicing of 7-cell PBGF was demonstrated with IL of $1.3 \mathrm{~dB}$ [76].

To achieve sub- $1 \mathrm{~dB}$ insertion losses, the move to bridge fibers acting as mode-field adapters was necessary. In 2014, MFD accommodation using a few-mode fiber to a 7-cell PBGF was published [20], showing the potential of bridge fibers formed by thermally-expanded core (TEC) fibers. Splice loss of only $0.73 \mathrm{~dB}$ was obtained for an SMF-TECPBGF interconnection.

\subsection{Fiber-Array Based Interconnection}

When we first came with the idea of an alternative HCF-SMF interconnection approach, the best interconnection result had not yet been reached by a splice, but by using an HCF connector [77] and a large-mode area (LMA) single-mode fiber acting as a mode-field adapter (afterwards spliced to SMF) with a benchmark IL of $0.3 \mathrm{~dB}$ and RL of $-31 \mathrm{~dB}$ thanks to a deposited anti-reflective (AR) coating on the LMA fiber.

Prior to HCFs, we already had some experience with interconnecting solid-core chalcogenide fibers to conventional SMFs, where AR coating was used to accommodate the difference in refractive indices and a bridge fiber was used to accommodate MFD. The deposition of AR coating or generally any optical coating was extremely appealing for HCFs, as fusion splicing prohibits the use of optical coatings due to high temperatures during splicing. Therefore, we developed a new alternative interconnection technology for HCFs, which, at that time, was envisioned to provide MFD accommodation, low IL and suppress unwanted back-reflections.

As a result, we published a low-loss, low-back-reflection reciprocal HCF-SMF interconnection in 2019 [23] based on the fiber-array technology and graded-index (GRIN) multimode fibers as mode-field adapters. In this first result we showed state-of-the-art IL per a single interconnection of $0.30 \mathrm{~dB}$ for fundamental mode coupling and RL of almost $-30 \mathrm{~dB}$, which are comparable values to [77]. However, in [77] the interconnection was based on a connectorized
PBGF and, thus, the interconnection was not permanent and hermetic as the interconnection we developed is. In the development of our interconnection technique, we also devised a new method for HOM content monitoring (seen in Fig. 9), which is described in detail in [23]. The basic principle of the interconnection is depicted in Fig. 10, where both fiber-arrays are then glued together at temperatures below $80^{\circ} \mathrm{C}$, thus also considered as a "cold splice" technique. Our interconnection can essentially work for any HCF with any solid-core fiber, while any optical coating can be deposited.

In our first result [23], we observed very low HOM excitation, which is welcomed in many HCF applications as is shown in Fig. 9. Nevertheless, as mentioned above, PBGFs are inherently multi-modal and HOMs propagate with low attenuation, so even with high HOM suppression PBGF still exhibits multi-modal behavior. The next logical step was to move to ARFs, which have currently surpassed PBGFs in most aspects (other than bend loss resistance). The most promising of all ARFs are NANFs.

Using our interconnection approach, we modified our graded-index mode-field adapters for NANFs and the prior results showed IL below $0.5 \mathrm{~dB}$ with $\mathrm{RL}$ of $-35 \mathrm{~dB}$ using an improved AR coating [78]. An image of an experimental NANF overlapped with its mode-field distribution can be seen in Fig. 11. As the NANF has a closer mode shape to a Gaussian than a PBGF and close to single-mode behavior, we expect to achieve record-low IL of the interconnection soon.

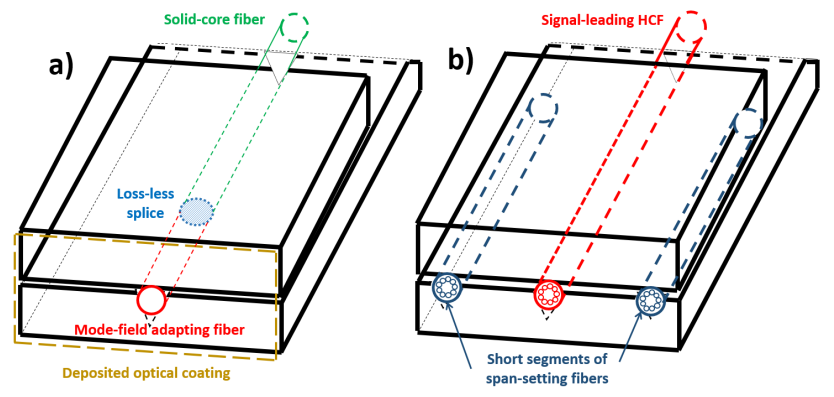

Fig. 10. Principle of the fiber-array-based interconnection of hollow-core to solid-core fiber, a) solid-core fiber with spliced mode-field adapting fiber segment in a 1-channel fiber-array, b) hollow-core fiber in a 3-channel fiberarray, where the side channels serve for precise gap setting.

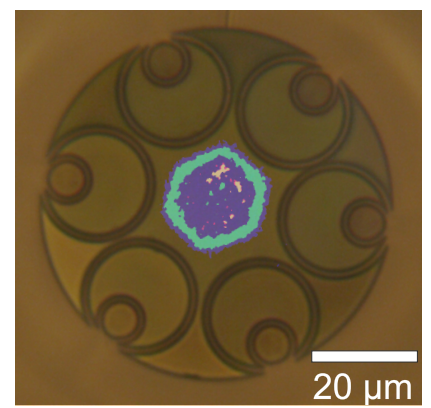

Fig. 11. NANF overlapped with its measured mode-field distribution. 


\subsection{Other Interconnection Solutions}

An interesting solution has recently appeared using micro-optic collimator technology [79], where IL of $0.53 \mathrm{~dB}$ was presented for a single SMF-HCF interconnection with RL better than $-45 \mathrm{~dB}$ and good HOM suppression $(>20 \mathrm{~dB})$.

A tapered SMF as a coupling option has been theoretically and experimentally investigated [80], where the taper was inserted into the ARF core area. The resulting IL was approximately $0.8 \mathrm{~dB}$ for an SMF-NANF coupling, whereas back-reflections were suppressed well below $-60 \mathrm{~dB}$ (considered as Fresnel-loss free). The design was based on a tapered coupling of an SMF-HCF published previously, in 2017, by R. Pennetta [41].

Regarding $\mathrm{HCF}$ to $\mathrm{HCF}$ interconnection, an interconnection has already been demonstrated via fusion splicing with only $0.16 \mathrm{~dB}$ average splice loss [81].

\section{Interconnected HCF Applications}

In this section we present an overview of the main application fields where our HCF-SMF interconnection technology can be advantageously used.

\subsection{HCF-Based Interferometers}

In interferometric applications, HCFs offer the advantages of low nonlinearity thanks to the negligible light-glass interaction and HCF thermal insensitivity [7].

The flagship representative among all fiber-optic interferometric sensors is the Sagnac interferometer acting as a fiber-optic gyroscope (FOG). Use of HCFs in FOGs is especially desired due to their low nonlinearity and thermal polarization stability. A proposal for a HCF-based FOG was presented in [15] using a 7-cell PBGF of $20 \mathrm{~m}$ length. HCF-SMF interconnection was found to be one of the key challenges for further FOG development. Mach-Zehnder interferometer based on HCFs has been predominantly used as a gas/pressure sensor, such as the one shown in [82].

Our interconnection technology brings the advantages of low IL, optical coatings deposition to reduce backreflection, fundamental mode excitation and also possible gas-cell formation (by adding gas inlets in the interconnection) which can serve to apply purge gases for further increase of interferometer stability and performance.

Recently, we have been focusing on fiber-based FabryPerot interferometers (FPIs) which permit us to build on our interconnection technique. Using a highly-reflective (>98\%) coating we created two long-length FPIs [16] with lengths of $5 \mathrm{~m}$ and $22 \mathrm{~m}$. Achieved finesse was over 120 for both FPIs with transmission peaks of only $47 \mathrm{kHz}$. Furthermore thermal stability of our HCF-based FPIs was evaluated and was measured to be 14.5 times better than for an identical FPI made of SMF.

\subsection{Data Transmission}

HCFs are especially suitable for data transmission thanks to their low latency [4], low nonlinearity [3], and in the case of NANFs, extreme bandwidth and low attenuation. In 2019, data transmission over a 1-km-long NANF was demonstrated, where the tested NANF exhibited bandwidth of $700 \mathrm{~nm}$ with attenuation of $6.6 \mathrm{~dB} / \mathrm{km}$ at $1550 \mathrm{~nm}$ which allowed $50 \mathrm{Gbit} / \mathrm{s}$ On-off keying (OOK) and $100 \mathrm{Gbit} / \mathrm{s}$ 4-level Pulse Amplitude Modulation (4PAM) signals [83]. The same year, 4.8-km-long NANF segment with attenuation of $1.18 \mathrm{~dB} / \mathrm{km}$ at $1550 \mathrm{~nm}$ was used in a recirculating loop. This allowed for a data transmission of over $341-\mathrm{km}$ long NANF link with better pre-forward error correction bit error rate than 3E-2 [84].

To enable NANF application in real optical networks, fusion splicing may serve well when back-reflections are not a limiting factor. Otherwise, our interconnection technology provides better performance. Nevertheless for all interconnection approaches long-term stability must be ensured.

\subsection{Gas Sensing}

HCFs have evolved significantly over the last two decades and are excellent candidates for highly sensitive gas sensing applications [85]. This is especially due to their almost $100 \%$ mode-field overlap with the studied gas analyte. HCFs also allow the possibility to construct long-length gas cells which substitute the need for conventional multi-path free-space cells [14]. Among HCFs, ARFs provide a homogeneous and low-defect structure with substantial mitigation of HOMs, thus becoming the most suitable choice to form gas cells. Further advantage of silica HCFs for gas sensing is their MIR transparency. Even though silica is opaque above $2.4 \mu \mathrm{m}$, thanks to the negligible overlap of the core mode with the glass material, silica HCFs can work up to $4.0-4.5 \mu \mathrm{m}$ with reasonable attenuation [43].

The common approach to analyzing gases is to use infra-red (IR) spectroscopy [86]. A complementary detection technique is Raman spectroscopy which is especially advantageous when studying multi-component gas analytes as it does not require a strict wavelength to match the respective absorption line [87].

Nevertheless, the gas-cell is mostly built in a laboratory environment where light is coupled via lens-systems. Alternatively, gas cells are sometimes fusion spliced to solid-core fibers resulting in higher IL and unwanted back-reflections.

Using our fiber-array interconnection technology we can either significantly suppress back-reflections or, as in the case of Fabry-Perot interferometers, we can increase the reflection and allow multi-path propagation to increase the interaction length by a factor of 10-100 depending on HCF attenuation and coating reflectivity. Furthermore, we can ensure fundamental mode excitation and thus reduce noise of the sensing system dramatically. 


\subsection{Other Application Fields}

Gas-filled MIR lasers based on HCFs [42] can also benefit from providing a permanent interconnection of HCF to solid-core fibers, most likely not SMFs, but MIR transparent fibers, such as fluoride (ZBLAN). Nevertheless, the interconnection methodologies (of both fusion splicing and using fiber-arrays) will need to be modified to work with other glass materials.

For high-power delivery, HCFs are extremely interesting due to their high damage threshold [5]. From particular power levels (depending on a continuous-wave or pulsed regime and on wavelength) HCFs, or more specifically ARFs, are the only option, as glass fibers are limited by the material damage threshold. Increasing power places higher requirements on the optical coatings, heat transfer from the interconnection and high HOM suppression. Our fiber-array approach has already shown very good HOM suppression, nevertheless efficient heat transfer and high-power optical coatings must still be investigated.

\section{Conclusion}

We have presented an overview of hollow-core optical fibers which are considered to be the future successors of conventional solid-core optical fibers, from their early stages all the way to current state-of-the-art antiresonant optical fibers.

Light guiding mechanisms of Bragg, photonic-bandgap and antiresonant fibers were discussed. Nested antiresonant nodeless fibers and conjoined-tube fibers are the two most promising antiresonant fiber designs for achieving ultra-low attenuation.

We have discussed interconnection options of hollowcore fibers to standard single-mode silica fibers. An alternative interconnection technique developed by our team was presented. Thanks to the mode-field adaptation using graded-index multimode fiber we achieved record-low insertion loss and also suppressed higher-order modes. Deposition of anti-reflective coating allowed us to reduce unwanted backreflections. Finally, cutting-edge application of hollow-core fibers have been summarized with respect to the advantages of our proposed interconnection technology.

Hollow-core optical fibers are undoubtedly the future of fiber-optic communication, gas sensing, metrology, ultraprecise interferometry or mid-infrared lasers. Therefore, they definitely are worthy of scientific attention.

\section{Acknowledgments}

We would like to thank the members of the Advanced Fibre Technologies \& Applications group, Optoelectronics Research Centre, Zepler Institute for Photonics and Nanoelectronics, University of Southampton for their collaboration in the hollow-core fiber research and for providing samples of photonic-bandgap and nested antiresonant nodeless fibers.

\section{References}

[1] ELLIS, A. D., MCCARTHY, M. E., KHATEEB, M. A. Z. A., et al Performance limits in optical communications due to fiber nonlinearity. Advances in Optics and Photonics, 2017, vol. 9, no. 3, p. 429-503. DOI: 10.1364/AOP.9.000429

[2] TAMURA, Y., SAKUMA, H., MORITA, K., et al. The first 0.14- $\mathrm{dB} / \mathrm{km}$ loss optical fiber and its impact on submarine transmission. Journal of Lightwave Technology, 2018, vol. 36, no. 1, p. 44-49. DOI: 10.1109/JLT.2018.2796647

[3] ROBERTS, P., COUNY, F., BIRKS, T., et al. Achieving low loss and low nonlinearity in hollow core photonic crystal fibers. Lasers and Electro-Optics, 2005, vol. 2, p. 1240-1242. DOI: 10.1109/CLEO.2005.202085

[4] KUSCHNEROV, M., MANGAN, B. J., GONG, K., et al. Transmission of commercial low latency interfaces over hollow-core fiber. Journal of Lightwave Technology, 2016, vol. 34, no. 2, p. 314-320. DOI: 10.1109/JLT.2015.2469144

[5] SHEPHARD, J., COUNY, F., RUSSELL, P., et al. Improved hollowcore photonic crystal fiber design for delivery of nanosecond pulses in laser micromachining applications. Applied Optics, 2005, vol. 44, no. 21 , p. 4582-4588. DOI: 10.1364/AO.44.004582

[6] POLETTI, F. Nested antiresonant nodeless hollow core fiberOptics Express, 2014, vol. 22, no. 20, p. 23807-23828. DOI: $10.1364 / \mathrm{OE} .22 .023807$

[7] SLAVÍK, R., MARRA, G., FOKOUA, E. N., et al. Ultralow thermal sensitivity of phase and propagation delay in hollow core optical fibres. Scientific Reports, 2015, vol. 5, p. 1-7. DOI: 10.1038/srep15447

[8] PRYAMIKOV, A. D., BIRIUKOV, A. S., KOSOLAPOV, A. F., et al. Demonstration of a waveguide regime for a silica hollow - core microstructured optical fiber with a negative curvature of the core boundary in the spectral region $>3.5 \mu \mathrm{m}$. Optics Express, 2011, vol. 19, no. 2 , p. 1441-1448. DOI: 10.1364/OE.19.001441

[9] BENABID, F., COUNY, F., KNIGHT, J. C., et al. Compact, stable and efficient all-fibre gas cells using hollow-core photonic crystal fibres. Nature, 2005, vol. 434, no. 7032, p. 488-491. DOI: 10.1038/nature03349.

[10] HUMBERT, G., KNIGHT, J. C., BOUWMANS, G., et al. Hollow core photonic crystal fibers for beam delivery. Optics Express, 2004, vol. 12, no. 8, p. 1477-1484. DOI: 10.1364/opex.12.001477

[11] GÉRÔME, F., DUPRIEZ, P., CLOWES, J., et al. High power tunable femtosecond soliton source using hollow-core photonic bandgap fiber, and its use for frequency doubling. Optics Express, 2008, vol. 16, no. 4, p. 2381-2386. DOI: 10.1364/OE.16.002381

[12] COUNY, F., BENABID, F., ROBERTS, P. J., et al. Generation and photonic guidance of multi-octave optical-frequency combs. Science, 2007, vol. 318, no. 5853, p. 1118-1121. DOI: $10.1126 /$ science. 1149091

[13] WHEELER, N. V., HEIDT, A. M., BADDELA, N. K., et al. Lowloss and low-bend-sensitivity mid-infrared guidance in a hollowcore-photonic-bandgap fiber. Optics Letters, 2014, vol. 39, no. 2, p. 295-298. DOI: 10.1364/OL.39.000295

[14] NAMPOOTHIRI, A. V. V., JONES, A. M., FOURCADE-DUTIN, C., et al. Hollow-core Optical Fiber Gas Lasers (HOFGLAS): A review [Invited]. Optical Materials Express, 2012, vol. 2, no. 7, p. 948-961. DOI: 10.1364/OME.2.000948

[15] TERREL, M. A., DIGONNET, M. J. F., FAN, S. Resonant fiber optic gyroscope using an air-core fiber. Journal of Lightwave Technology, 2012, vol. 30, no. 7, p. 931-937. DOI: 10.1109/JLT.2011.2177959 
[16] DING, M., KOMANEC, M., SUSLOV, D., et al. Long-length and thermally stable high-finesse Fabry-Perot interferometers made of hollow core optical fiber. Journal of Lightwave Technology, 2020, vol. 38, no. 8, p. 2423-2427. DOI: 10.1109/JLT.2020.2973576

[17] JASION, G. T., BRADLEY, T. D., HARRINGTON, K., et al. Hollow Core NANF with $0.28 \mathrm{~dB} / \mathrm{km}$ attenuation in the $\mathrm{C}$ and L bands. In Optical Fiber Communication Conference and Exhibition Postdeadline Papers. San Diego (USA), 2020, p. 1-3. DOI: $10.1364 / \mathrm{OFC} .2020 . \mathrm{Th} 4 \mathrm{~B} .4$

[18] CHEN, Y., LIU, Z., SANDOGHCHI, S. R., et al. Multikilometer long, longitudinally uniform hollow core photonic bandgap fibers for broadband low latency data transmission. Journal of Lightwave Technology, 2016, vol. 34, no. 1, p. 104-113. DOI: 10.1109/JLT.2015.2476461

[19] JASION, G. T., POLETTI, F., SHRIMPTON, J. S., et al. Volume manufacturing of hollow core photonic band gap fibers: Challenges and opportunities. In Optical Fiber Communication Conference and Exhibition. Los Angeles (USA), 2015, p. 1-3. DOI: 10.1364/OFC.2015

[20] GAO, S., WANG, Y., TIAN, C., et al. Splice loss optimization of a photonic bandgap fiber via a high V-number fiber. IEEE Photonics Technology Letters, 2014, vol. 26, no. 21, p. 2134-2137. DOI: 10.1109/LPT.2014.2349519

[21] COUNY, F., BENABID, F., LIGHT, P. S., Reduction of Fresnel backreflection at splice interface between hollow core PCF and singlemode fiber. IEEE Photonics Technology Letters, 2007, vol. 19, no. 13, p. 1020-1022. DOI: 10.1109/LPT.2007.898770

[22] MILLER, G. A., CRANCH, G. A., Reduction of intensity noise in hollow core optical fiber using angle-cleaved splices. IEEE Photonics Technology Letters, 2016, vol. 28, no. 4, p. 414-417. DOI: 10.1109/LPT.2015.2496873

[23] KOMANEC, M., SUSLOV, D., ZVÁNOVEC, S., et al. Low-loss and low-back-reflection hollow-core to standard fiber interconnection. IEEE Photonics Technology Letters, 2019, vol. 31, no. 10, p. 723-726. DOI: 10.1109/LPT.2019.2902635

[24] THOMSON, J. J. Notes on Recent Researches in Electricity and Magnetism: Intended as a Sequel to Professor Clerk-Maxwell's Treatise on Electricity and Magnetism. 1893. ISBN: 978-1332470754

[25] LORD RAYLEIGH F. R. S. XVIII. On the passage of electric waves through tubes, or the vibrations of dielectric cylinders. The London, Edinburgh, and Dublin Philosophical Magazine and Journal of Science, 1897, vol. 43, no. 261, p. 125-132. DOI: $10.1080 / 14786449708620969$

[26] MARCATILI, E. A. J., SCHMELTZER, R. A. Hollow metallic and dielectric waveguides for long distance optical transmission and lasers. The Bell System Technical Journal, 1964, vol. 43, no. 4, p. 1783-1809. DOI: $10.1002 / \mathrm{j} .1538-7305.1964 . t b 04108 . x$

[27] HIDAKA, T., MORIKAWA, T., SHIMADA, J. Hollow-core oxideglass cladding optical fibers for middle-infrared region. Journal of Applied Physics. 1981, vol. 52, no. 7, p. 4467-4471. DOI: $10.1063 / 1.329373$

[28] NAGANO, N., SAITO, M., MIYAGI, M., et al. $\mathrm{TiO}_{2}-\mathrm{SiO}_{2}$ based glasses for infrared hollow waveguides. Applied Optics, 1991, vol. 30, no. 9, p. 1074-1079. DOI: 10.1364/AO.30.001074

[29] SAITO, Y., KANAYA, T., NOMURA, A., et al. Experimental trial of a hollow-core waveguide used as an absorption cell for concentration measurement of $\mathrm{NH}_{3}$ gas with a $\mathrm{CO}_{2}$ laser. Optics Letters, 1993, vol. 18 , no. 24 , p. $2150-2152$. DOI: 10.1364/OL.18.002150

[30] SIRKIS, J. S., BRENNAN, D. D., PUTMAN, M. A., et al. In-line fiber etalon for strain measurement. Optics Letters, 1993, vol. 18, no. 22, p. 1973-1975. DOI: 10.1364/OL.18.001973
[31] RENN, M. J., MONTGOMERY, D., VDOVIN, O., et al. Laser-guided atoms in hollow-core optical fibers. Physical Review Letters, 1995, vol. 75, no. 18, p. 3253-3256. DOI: 10.1103/PhysRevLett.75.3253

[32] TEMELKURAN, B., HART, S. D., BENOIT, G., et al. Wavelengthscalable hollow optical fibres with large photonic bandgaps for $\mathrm{CO} 2$ laser transmission. Nature, 2002, vol. 420, no. 6916, p. 650-653. DOI: $10.1038 /$ nature 01275

[33] VIENNE, G., XU, Y., JAKOBSEN, C., et al. Ultra-large bandwidth hollow-core guiding in all-silica Bragg fibers with nanosupports. Optics Express, 2004, vol. 12, no. 15, p. 3500-3508. DOI: 10.1364/OPEX.12.003500

[34] KNIGHT, J. C., BIRKS, T. A., RUSSELL, P. S. J., et al. Allsilica single-mode optical fiber with photonic crystal cladding. Optics Letters, 1996, vol. 21, no. 19, p. 1547-1549. DOI: $10.1364 /$ OL.21.001547

[35] YABLONOVITCH, E. Inhibited spontaneous emission in solid-state physics and electronics. Physical Review Letters, 1987, vol. 58, no. 20, p. 2059-2062. DOI: 10.1103/PhysRevLett.58.2059

[36] JOHN, S. Strong localization of photons in certain disordered dielectric superlattices. Physical Review Letters, 1987, vol. 58, no. 23, p. 2486-2489. DOI: 10.1103/PhysRevLett.58.2486

[37] BIRKS, T. A., KNIGHT, J. C., RUSSELL, P. S. J. Endlessly singlemode photonic crystal fiber. Optics Letters, 1997, vol. 22, no. 13, p. 961-963. DOI: $10.1364 /$ OL.22.000961

[38] MOGILEVTSEV, D., BIRKS, T. A., RUSSELL, P. S. J. Groupvelocity dispersion in photonic crystal fibers. Optics Letters, 1998, vol. 23, no. 21, p. 1662-1664. DOI: 10.1364/OL.23.001662

[39] RANKA, J. K., WINDELER, R. S., STENTZ, A. J. Visible continuum generation in air-silica microstructure optical fibers with anomalous dispersion at $800 \mathrm{~nm}$. Optics Letters, 2000, vol. 25, no. 1, p. 25-27. DOI: $10.1364 /$ OL. 25.000025

[40] CREGAN, R., MANGAN, B., KNIGHT, J., et al. Single-mode photonic band gap guidance of light in air. Science, 1999, vol. 285, no. 5433 , p. $1537-1539$. DOI: $10.1126 /$ science. 285.5433 .1537

[41] PENNETTA, R., XIE, S., LENAHAN, F., et al. Fresnelreflection-free self-aligning nanospike interface between a stepindex fiber and a hollow-core photonic-crystal-fiber gas cell. Physical Review Applied, 2017, vol. 8, no. 1, p. 1-6. DOI: 10.1103/PhysRevApplied.8.014014

[42] DADASHZADEH, N., THIRUGNANASAMBANDAM, M. P., WEERASINGHE, H. W. K., et al. Near diffraction-limited performance of an OPA pumped acetylene-filled hollow-core fiber laser in the mid-IR. Optics Express, 2017, vol. 25, no. 12, p. 13351-13358. DOI: $10.1364 / \mathrm{OE} .25 .013351$

[43] KLIMCZAK, M., DOBRAKOWSKI, D., GHOSH, A. N., et al. Nested capillary anti-resonant silica fiber with mid-infrared transmission and low bending sensitivity at $4000 \mathrm{~nm}$. Optics Letters, 2019, vol. 44, no. 17, p. 4395-4398. DOI: 10.1364/OL.44.004395

[44] VENKATARAMAN, N., GALlAGHER, M. T., SMITH, C. M., et al. Low loss $(13 \mathrm{~dB} / \mathrm{km})$ air core photonic band-gap fibre. In European Conference on Optical Communication (ECOC). Copenhagen (Denmark), 2002, p. 1-2.

[45] MANGAN, B. J., FARR, L., LANGFORD, A., et al. Low loss $(1.7 \mathrm{~dB} / \mathrm{km})$ hollow core photonic bandgap fiber. In Optical Fiber Communication Conference (OFC). Los Angeles (USA), 2004, p. $1-3$.

[46] ROBERTS, P. J., COUNY, F., SABERT, H., et al. Ultimate low loss of hollow-core photonic crystal fibres. Optics Express, 2005, vol. 13, no. 1, p. 236-244. DOI: 10.1364/OPEX.13.000236 
[47] BENABID, F., KNIGHT, J. C., ANTONOPOULOS, G., et al. Stimulated raman scattering in hydrogen-filled hollow-core photonic crystal fiber. Science, 2002 , vol. 298 , no. 5592 , p. 399-402, DOI: $10.1126 /$ science. 1076408

[48] PEARCE, G. J., WIEDERHECKER, G. S., POULTON, C. G., et al. Models for guidance in Kagome-structured hollow-core photonic crystal fibres. Optics Express, 2007, vol. 15, no. 20, p. 12680-12685. DOI: $10.1364 / \mathrm{OE} .15 .012680$

[49] WANG, Y. Y., COUNY, F., ROBERTS, P. J., et al. Low loss broadband transmission in optimized core-shape Kagome hollow-core PCF. In Conference on Lasers and Electro-Optics (CLEO/QELS). San Jose (USA), 2010, p. 1-2. DOI: 10.1364/CLEO.2010

[50] WHEELER, N., BRADLEY, T., HAYES, J., et al. Low loss Kagome fiber in the $1 \mu \mathrm{m}$ wavelength region. In Speciality Optical Fibers Meeting at the Advanced Photonics Congress. Vancouver (Canada), 2016, p. 1. DOI: 10.1364/sof.2016.som3f.2

[51] FÉVRIER, S., BEAUDOU, B., VIALE, P. Understanding origin of loss in large pitch hollow-core photonic crystal fibers and their design simplification. Optics Express, 2010, vol. 18, no. 5, p. 5142-5150. DOI: $10.1364 / \mathrm{OE} .18 .005142$

[52] YU, F., WADSWORTH, W. J., KNIGHT, J. C. Low loss silica hollow core fibers for 3-4 $\mu \mathrm{m}$ spectral region. Optics Express, 2012, vol. 20, no. 10 , p. $11153-11158$. DOI: $10.1364 /$ OE.20.011153

[53] DEBORD, B., AMSANPALLY, A., CHAFER, M., et al. Ultralow transmission loss in inhibited-coupling guiding hollow fibers. Optica, 2017, vol. 4, no. 2, p. 209-217. DOI: 10.1364/OPTICA.4.000209

[54] GAO, S. F., WANG, Y. Y., DING, W., et al. Hollow-core conjoinedtube negative-curvature fibre with ultralow loss. Nature Communications, 2018, vol. 9, no. 1, p. 1-6. DOI: 10.1109/IPCon.2016.7831157

[55] BRADLEY, T. D., HAYES, J. R., CHEN, Y., et al. Record low-loss $1.3 \mathrm{~dB} / \mathrm{km}$ data transmitting antiresonant hollow core fibre. In European Conference on Optical Communication (ECOC). Rome (Italy), 2018, p. 1-3. DOI: 10.1109/ECOC.2018.8535324

[56] BRADLEY, T. D., JASION, G. T., HAYES, J. R., et al. Antiresonant hollow core fibre with $0.65 \mathrm{~dB} / \mathrm{km}$ attenuation across the $\mathrm{C}$ and $\mathrm{L}$ telecommunication bands. In 45th European Conference on Optical Communication (ECOC). Dublin (Ireland), 2019, p. 1-4. DOI: $10.1049 / \mathrm{cp} .2019 .1028$

[57] JASION, G. T., SANDOGHCHI, S. R., CHEN, Y., et al. Novel fluid dynamics model to predict draw of hollow core photonic band-gap fibres. In European Conference on Optical Communication (ECOC). Cannes (France), 2014, p. 1-3. DOI: 10.1109/ECOC.2014.6964003

[58] RUSSELL, P. S. Photonic-crystal fibers. Journal of Lightwave Technology, 2006 , vol. 24 , no. 12, p. 4729-4749. DOI: $10.1109 / J L T .2006 .885258$

[59] POLETTI, F., PETROVICH, M. N., RICHARDSON, D. J. Hollow-core photonic bandgap fibers: technology and applications. Nanophotonics, 2013, vol. 2, no. 5-6, p. 315-340. DOI: 10.1515/nanoph-2013-0042

[60] BARKOU, S. E., BROENG, J., BJARKLEV, A. Silica-air photonic crystal fiber design that permits waveguiding by a true photonic bandgap effect. Optics Letters, 1999, vol. 24, no. 1, p. 46-48. DOI: $10.1364 /$ OL.24.000046

[61] MARADUDIN, A., MCGURN, A. Out of plane propagation of electromagnetic waves in a two-dimensional periodic dielectric medium. Journal of Modern Optics, 1994, vol. 41, no. 2, p. 275-284. DOI: $10.1080 / 09500349414550321$

[62] BROENG, J., BARKOU, S. E., SøNDERGAARD, T., et al. Analysis of air-guiding photonic bandgap fibers. Optics Letters, 2000, vol. 25, no. 2 , p. 96-98. DOI: $10.1364 /$ OL.25.000096
[63] MORTENSEN, N. A., NIELSEN, M. D. Modeling of realistic cladding structures for air-core photonic bandgap fibers. Optics Letters, 2004, vol. 29, no. 4, p. 349-351. DOI: 10.1364/OL.29.000349

[64] ZAMANI AGHAIE, K., FAN, S., DIGONNET, M. J. F. Birefringence analysis of photonic-bandgap fibers using the hexagonal Yee's cell. IEEE Journal of Quantum Electronics, 2010, vol. 46, no. 6, p. 920-930. DOI: 10.1109/JQE.2010.2040369

[65] LitCHINITSER, N. M., ABEELUCK, A. K., HEADLEY, C., et al. Antiresonant reflecting photonic crystal optical waveguides. Optics Letters, 2002, vol. 27, no. 18, p. 1592-1594. DOI: $10.1364 /$ OL.27.001592

[66] RENVERSEZ, G., BOYER, P., SAGRINI, A. Antiresonant reflecting optical waveguide microstructured fibers revisited: A new analysis based on leaky mode coupling. Optics Express, 2006, vol. 14, no. 12, p. 5682-5687. DOI: 10.1364/OE.14.005682

[67] WEI, C., WEIBLEN, R. J., MENYUK, C. R., et al. Negative curvature fibers. Advances in Optics and Photonics, 2017, vol. 9, no. 3, p. 504-561. DOI: 10.1364/AOP.9.000504

[68] CHOUDHURY, P., YOSHINO, T. A rigorous analysis of the power distribution in plastic clad annular core optical fibers. Optik, 2002, vol. 113, no. 11, p. 481-488. DOI: 10.1078/0030-4026-00195

[69] WEI, C., ALVAREZ, O., CHENARD, F., et al. Empirical glass thickness for chalcogenide negative curvature fibers. In IEEE Summer Topicals Meeting Series (SUM). Nassau (Bahamas), 2015, p. 187-188. DOI: 10.1109/PHOSST.2015.7248259

[70] JUNG, Y., SLEIFFER, V. A. J. M., BADDELA, N., et al. First demonstration of a broadband 37-cell hollow core photonic bandgap fiber and its application to high capacity mode division multiplexing. In Optical Fiber Communication Conference and Exposition and the $\mathrm{Na}$ tional Fiber Optic Engineers Conference (OFC/NFOEC). Anaheim (USA), 2013, p. 1-3. DOI: 10.1364/OFC.2013

[71] MORIOKA, T., AWAJI, Y., RYF, R., et al. Enhancing optical communications with brand new fibers. IEEE Communications Magazine, 2012, vol. 50, no. 2, p. 31-42. DOI: 10.1109/MCOM.2012.6146483

[72] NICHOLSON, J. W., YABLON, A. D., FINI, J. M., et al. Measuring the modal content of large-mode-area fibers. IEEE Journal of Selected Topics in Quantum Electronics, 2009, vol. 15, no. 1, p. 61-70. DOI: $10.1109 /$ JSTQE.2008.2010239

[73] RIKIMI, S., CHEN, Y., BRADLEY, T., et al. Long-term behaviour of water vapour absorption in hollow core fibres. In Sixth International Workshop on Specialty Optical Fibers and Their Applications (WSOF). Charleston (USA), 2019, p. 1-6.

[74] XIAO, L., JIN, W., DEMOKAN, M. S., et al. Fabrication of selective injection microstructured optical fibers with a conventional fusion splicer. Optics Express, 2005, vol. 13, no. 22, p. 9014-9022. DOI: 10.1364/OPEX.13.009014

[75] THAPA, R., KNABE, K., CORWIN, K. L., et al. Arc fusion splicing of hollow-core photonic bandgap fibers for gas-filled fiber cells. Optics Express, 2006, vol. 14, no. 21, p. 9576-9583. DOI: $10.1364 / \mathrm{OE} .14 .009576$

[76] WU, C., SONG, J., ZHANG, Z., et al. High strength fusion splicing of hollow-core photonic bandgap fiber and single-mode fiber. In Australian Conference on Optical Fibre Technology. Sydney (Australia), 2016. DOI: 10.1364/ACOFT.2016.AW4C.7

[77] NICHOLSON, J. W., MANGAN, B., MENG, L., et al. Low-loss, low return-loss coupling between SMF and single-mode, hollow-core fibers using connectors. In Conference on Lasers and Electro-Optics (CLEO) - Laser Science to Photonic Applications. San Jose (USA), 2014, p. 1-2. DOI: 10.1364/CLEO.AT.2014 
[78] SUSLOV, D., KOMANEC, M., ZVÁNOVEC, S., et al. Highlyefficient and low return-loss coupling of standard and antiresonant hollow-core fibers. In Frontiers in Optics + Laser Science. Washington, DC (USA), 2019. DOI: 10.1364/FIO.2019.FW5B.2

[79] JUNG, Y., KIM, H., CHEN, Y., et al. Compact micro-optic based components for hollow core fibers. Optics Express, 2020, vol. 28, no. 2, p. 1518-1525. DOI: 10.1364/OE.28.001518

[80] HUANG, W., CUI, Y., LI, X., et al. Low-loss coupling from single-mode solid-core fibers to anti-resonant hollow-core fibers by fiber tapering technique. Optics Express, 2019, vol. 27, no. 26, p. 37111-37121. DOI: 10.1364/OE.27.037111

[81] WOOLER, J. P., GRAY, D., POLETTI, F., et al. Robust low loss splicing of hollow core photonic bandgap fiber to itself. In Optical Fiber Communication Conference and Exposition and the National Fiber Optic Engineers Conference (OFC/NFOEC). Anaheim (USA), 2013, p. 1-3. DOI: 10.1364/OFC.2013.OM3I.5

[82] NAZERI, K., AHMED, F., AHSANI, V., et al. Hollow-core photonic crystal fiber mach-zehnder interferometer for gas sensing. Sensors, 2020, vol. 20, p. 1-12. DOI: 10.3390/s20102807

[83] SAKR, H., BRADLEY, T. D., HONG, Y., et al. Ultrawide bandwidth hollow core fiber for interband short reach data transmission. In $O p$ tical Fiber Communications Conference and Exhibition (OFC). San Diego (USA), 2019, p. 1-3. DOI: 10.1109/JLT.2019.2943178

[84] NESPOLA, A., STRAULLU, S., BRADLEY, T., et al. Record PM16QAM and PM-QPSK transmission distance $(125$ and $340 \mathrm{~km})$ over hollow-core-fiber. In 45th European Conference on Optical Communication (ECOC). Dublin (Ireland), 2019, p. 1-4. DOI: $10.1049 /$ cp.2019.1019

[85] DEBORD, B., FOUED, A., VINCETTI, L., et al. Hollow-core fiber technology: The rising of "Gas Photonics". Fibers, 2019, vol. 7, p. 1-16. DOI: 10.3390/fib7020016

[86] YANG, F., JIN, W., CAO, Y., et al. Towards high sensitivity gas detection with hollow-core photonic bandgap fibers. Optics Express, 2014, vol. 22, no. 20, p. 24894-24907. DOI: 10.1364/OE.22.024894
[87] KNEBL, A., YAN, D., POPP, J., et al. Fiber enhanced raman gas spectroscopy. TrAC Trends in Analytical Chemistry, 2018, vol. 103, p. 230-238. DOI: https://doi.org/10.1016/j.trac.2017.12.001

\section{About the Authors ...}

Matěj KOMANEC was born in 1984. He received his M.S. and Ph.D. degrees in Radioelectronics from the Czech Technical University in Prague (CTU) in 2009 and 2014, respectively. His research interests include specialty optical fibers, hollow-core fibers, optical interconnects, fiber-optic sensing, radio-over fiber and microwave photonics. He is a member of the Optical Society of America.

Daniel DOUSEK is a Ph.D. student at CTU. He received his M.S. degree in Radioelectronics from CTU in 2019. His current research interests include specialty optical fibers, optical components and interferometry.

Dmytro SUSLOV is a Ph.D. student at CTU. He received his M.S. degree in Radioelectronics from the CTU in 2016. His current research interests include specialty optical fibers, nonlinear optics, optical interconnects.

Stanislav ZVÁNOVEC received M.Sc. in 2002, a Ph.D. in 2006 at CTU. Now he is a full professor and deputy-head of the Department of Electromagnetic Field at the Faculty of Electrical Engineering, CTU. He leads a Free-space and fiber optics team from Faculty of Electrical Engineering, CTU and several research projects. His current research interests include wireless optical communications, visible light communications, remote sensing and optical fiber sensors. 